hippocampal place cells ${ }^{9}$. Our model may also represent an extension of operant conditioning into useful real-world applications, such as search and rescue in areas of urban destruction and landmine detection. Combined with electronic sensing and navigation technology, a guided rat can be developed into an effective 'robot' that will possess several natural advantages over current mobile robots. Moreover, the ability to receive brain sensory activity remotely ${ }^{10}$ and interpret it accurately could allow a guided rat to function as both a mobile robot and a biological sensor.

Sanjiv K. Talwar ${ }^{\star}$, Shaohua $\mathrm{Xu}^{*}$,

Emerson S. Hawley*, Shennan A. Weiss*, Karen A. Moxon $\dagger$, John K. Chapin ${ }^{\star}$

${ }^{*}$ Department of Physiology and Pharmacology,

State University of New York, Downstate Medical

\section{Development \\ Linguistic ability and early language exposure}

or more than 100 years, the scientific and educational communities have thought that age is critical to the outcome of language learning ${ }^{1,2}$, but whether the onset and type of language experienced during early life affects the ability to learn language is unknown. Here we show that deaf and hearing individuals exposed to language in infancy perform comparably well in learning a new language later in life, whereas deaf individuals with little language experience in early life perform poorly, regardless of whether the early language was signed or spoken and whether the later language was spoken or signed. These findings show that language-learning ability is determined by the onset of language experience during early brain development, independent of the specific form of the experience.

The ability to learn language, whether spoken or signed, declines with age ${ }^{3-6}$. How the onset and type of the initial language experience contributes to this criticalperiod phenomenon is unclear. This question cannot be investigated by studying hearing individuals only, because the factors of age and experience are inseparable in these individuals - all hearing babies experience language from birth. But the question can be investigated by studying individuals who were born deaf, because they often do not experience any language until they are enrolled in special programmes ${ }^{7,8}$. We therefore compared the language-learning capacities of deaf and hearing individuals as a function of early language experience.

We first investigated whether early experience of a spoken language could facilitate subsequent learning of a signed language. We tested two groups of adults who had
Centre, 450 Clarkson Avenue, Brooklyn, New York 11203, USA

e-mail: stalwar@netmail.hscbklyn.edu $\dagger$ School of Biomedical Engineering, Drexel University, 3141 Chestnut Street, Philadelphia, Pennsylvania 19104, USA

1. Skinner, B. F. The Behavior of Organisms: An Experimental Analysis (Appleton-Century-Crofts, New York, 1938).

2. Loucks, R. B. J. Comp. Psychol. 16, 439-444 (1933).

3. Olds, J. \& Milner, P. J. Comp. Physiol. Psychol. 47, 419-427 (1954).

4. Olds, M. E. \& Fobes, J. L. Annu. Rev. Psychol. 32, 523-574 (1981)

5. Doty, R. W. Annu. Rev. Psychol. 20, 289-320 (1969).

6. Romo, R., Hernández, A., Zainos, A., Brody, C. \& Lemus, L. Neuron 26, 273-278 (2000).

7. Deutsch, J. A. J. Theor. Biol. 4, 193-214 (1963).

8. Gallistel, C. R. J. Comp. Physiol. Psychol. 69, 713-721 (1969).

9. Fukuda, M., Kobayashi, T., Bures, J. \& Ono, T. J. Neurosci. Methods 44, 121-131 (1992).

10. Hawley, E. S., Hargeaves, E. L., Kubie, J. L., Rivard, B. \&

Muller, R. U. Hippocampus (in the press)

Competing financial interests: declared none.

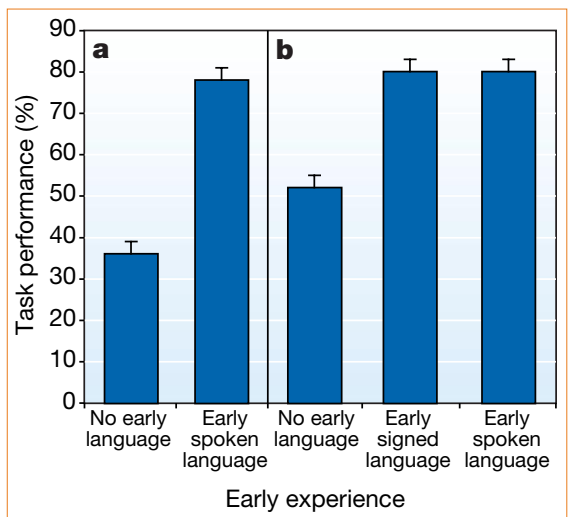

Figure 1 Effects of early experience on later language learning. a, American Sign Language (ASL) performance of deaf adults who had experienced no language in early life, and of deaf adults who had experienced spoken language in early life. Subjects were tested using a task requiring recall of complex ASL sentences. b, English performance of deaf adults who had had no experience of language in early life, of deaf adults who had experienced ASL in infancy, and of hearing adults who had experienced a spoken language other than English in infancy. Subjects were tested using a task requiring judgements of whether complex English sentences given in print were grammatically correct; chance performance is $50 \%$. Further details are available from the authors.

learned American Sign Language (ASL) at school between the matched ages of 9 and 15 years and who had used it for over two decades. One group $(n=9)$ was born hearing, had experienced spoken English in early life, and had later learned ASL after becoming profoundly deaf $(\geqslant 90$ decibels) as a result of viral infection; the second group $(n=9)$ was born profoundly deaf and had had little experience of language before being exposed to ASL in school (auditory speech-perception abilities were at chance levels even with hearing aids). Deaf adults who had little experience of language in early life showed low levels of ASL performance; in contrast, late-deafened adults showed high levels of ASL performance (Fig. 1; paired $t=4.17$; d.f., 8 ; $P<0.001$ ).
We next investigated whether early experience of a signed language facilitates subsequent learning of a spoken language. We tested three groups of adults who had learned English in school at comparable ages between 4 and 13 years and who had used it for over 12 years. One group $(n=14)$ was born profoundly deaf and had had little language experience before being exposed to ASL in school; the second group $(n=13)$ was born profoundly deaf and had experienced ASL in infancy; the third group $(n=13)$ was born hearing and had experienced various spoken languages in infancy (Urdu, French, German, Italian or Greek). Deaf and hearing adults who had experienced either a signed or a spoken language in early life showed similarly high levels of performance on the later learned language, English, whereas deaf adults who had little experience of language in early life showed low levels of performance (Fig. 1; $F_{2,37}=11.32$, $P<0.0001$ ).

Our results show that the ability to learn language arises from a synergy between early brain development and language experience, and is seriously compromised when language is not experienced during early life. This is consistent with current knowledge about how experience affects visual development in animals ${ }^{9}$ and humans ${ }^{10}$, and about learning and brain development in animals ${ }^{11,12}$. The timing of the initial language experience during human development strongly influences the capacity to learn language throughout life, regardless of the sensorimotor form of the early experience.

Rachel I. Mayberry ${ }^{\star}$, Elizabeth Lock $\dagger$, Hena Kazmi

* School of Communication Sciences and Disorders, McGill University, 1266 Pine Avenue West,

Montreal, Quebec H3G 1A8, Canada

e-mail: rachel.mayberry@mcgill.ca

$\dagger$ Faculty of Medicine, University of Ottawa,

4418-501 Smyth Road, Ottawa,

Ontario K1H 8L6, Canada

$\ddagger$ School of Communication Sciences and Disorders,

University of Western Ontario, Elborn College,

London, Ontario N6G 1H1, Canada

1. Colombo, J. Psychol. Bull. 91, 260-275 (1982).

2. Lenneberg, E. Biological Foundations of Language (Wiley, New York, 1967)

3. Johnson, J. \& Newport, E. Cogn. Psychol. 21, 60-69 (1989).

4. Newport, E. Cogn. Sci. 14, 11-28 (1990).

5. Mayberry, R. I. \& Eichen, E. J. Mem. Lang. 30, 486-512 (1991).

6. Emmorey, K., Bellugi, U., Friederici, A. \& Horn, P. Appl. Psycholing. 16, 1-23 (1995).

7. Mayberry, R. I. J. Speech Hearing Res. 36, 51-68 (1993).

8. Mayberry, R. I. in Child Neuropsychology (eds Segalowitz, S. J. \& Rapin, I.) (Elsevier, Amsterdam, in the press).

9. Wiesel, T. N. Nature 299, 583-591 (1982).

10. Goldberg, M. C., Maurer, D., Lewis, T. L. \& Brent, H. P. Dev. Neuropsychol. 19, 55-81 (2001).

11. Greenough, W. T. \& Black, J. E. in Developmental Behavioral Neuroscience (eds Gunna, M. R. \& Nelson, C. A.) 155-200 (Erlbaum, Hillsdale, New Jersey, 1992).

12. Kolb, B., Forgie, M., Gibb, R., Gorny, G. \& Rowntree, S.

Neurosci. Biobehav. Rev. 22, 143-159 (1998).

Competing financial interests: declared none. 